CLINICAL STUDY

\title{
Functional glucocorticoid receptor gene variants do not underlie the high variability of 17 -hydroxyprogesterone screening values in healthy newborns
}

\author{
Felix Schreiner, Magdalini Tozakidou, Rita Maslak, Ute Holtkamp ${ }^{1}$, Michael Peter ${ }^{1}$, Bettina Gohlke \\ and Joachim Woelfle \\ Pediatric Endocrinology Division, Children's Hospital, University of Bonn, Adenauerallee 119, 53113 Bonn, Germany and ${ }^{1}$ Screening-Labor Hannover, \\ 30430 Hannover, Germany \\ (Correspondence should be addressed to J Woelfle; Email: joachim.woelfle@ukb.uni-bonn.de)
}

\begin{abstract}
Objective: 17-Hydroxyprogesterone (17-OHP) screening for classical congenital adrenal hyperplasia $(\mathrm{CAH})$ is part of many newborn screening programs worldwide. Cut-off values are relatively high, and screening sensitivity does not reach $100 \%$. Recently, the glucocorticoid receptor (GR) N363S-variant has been linked to relatively low degree of virilization and comparatively lower 17-OHP serum concentrations in clinically diagnosed female $\mathrm{CAH}$ patients. We sought to determine whether functional GR gene variants, either increasing (N363S, BclI) or decreasing GR sensitivity (R23K), underlie the variable 17-OHP screening levels in healthy newborns.

Design: GR genotypes were compared with 17-OHP screening values in 1000 random samples from routine screening. 17-OHP was measured by conventional immunoassay (TRFIA) and a liquid chromatography-tandem mass spectrometry method (LC-MS/MS), which has been shown to increase screening specificity by steroid profiling and avoiding cross-reactions of the 17-OHP-antibody.

Results: There was no significant association of 17-OHP with GR genotypes, even after inclusion of gestational and postnatal age as covariates. However, among LC-MS/MS steroid measurements, we observed some unexpected trends, including lower 11-deoxycortisol concentrations in both 363S- and $23 \mathrm{~K}$-carriers. For carriers of the frequent BclI variant, linear regression analysis revealed a significant increase of 4-androstenedione levels with every mutant allele inherited.

Conclusions: Functional GR variants do not underlie the variation of $17-\mathrm{OHP}$ values observed in healthy individuals. However, whether and to which extent genetically determined differences in individual GR sensitivity influence 17-OHP screening levels in conditions of a pathological hypothalamus-pituitary-adrenal gland-axis stimulation and thus may explain false-negative screening results in those affected by $\mathrm{CAH}$ remains to be investigated.
\end{abstract}

European Journal of Endocrinology 160 667-673

\section{Introduction}

Classical congenital adrenal hyperplasia (CAH) due to 21-hydroxylase (CYP21) deficiency is an autosomalrecessive inherited disorder and affects $\sim 1$ of 14000 births worldwide. Clinical symptoms are consequences both of reduced corticosteroid synthesis after and of excessive precursor steroid levels before the enzyme block. The more severe salt-wasting $\mathrm{CAH}$ newborns are at risk to develop life-threatening salt-loss crises, and female newborns frequently exhibit severely virilized genitalia, which can lead to gender mis-assignment. Excessive secretion of 17-hydroxyprogesterone (17$\mathrm{OHP}$ ) enables detection of $\mathrm{CAH}$ already in the neonate. 17-OHP screening has therefore become a valuable tool to prevent newborns from life-threatening salt-loss crises as well as gender mis-assignment (1).
We and others have shown that screening sensitivity does not reach $100 \%(2-4)$. This can be put down to a high variability of 17-OHP screening levels in healthy newborns and thus the need of relatively high cut-off values. In conventional screening assays, high cut-off values mainly derive from cross-reactions of the 17-OHP antibody. Nonetheless, a considerable variability of 17-OHP levels in healthy individuals is also seen in extracted steroid assays. Moreover, aside from a relatively strong genotype-phenotype correlation concerning the impairment of mineralocorticoid synthesis in classical $\mathrm{CAH}$, there is a high variability in the degree of external genitalia virilization in affected females $(5,6)$. Background genetic factors such as individual androgen receptor (AR) sensitivity due to nCAG length polymorphisms within the AR gene have been suggested to explain parts of the phenotypical 
variability (7). Interestingly, genetically determined increased glucocorticoid receptor (GR) sensitivity in 363S-carriers of the GR N363S variant has recently been found to be associated with less severe virilization and lower 17-OHP levels in females at the time CAH was diagnosed clinically (8). We therefore speculated whether functional GR variants, by modulating the individual setpoint of the neonatal HPA-axis, might explain the wide range of 17-OHP levels observed in unaffected individuals. To test this hypothesis, we compared neonatal steroid hormone levels including 17-OHP with genotypes for three GR gene variants previously shown to either increase (N363S, BclI) or decrease (R23K) GR sensitivity in vivo (9).

\section{Samples and methods}

\section{Screening samples and hormone measurements}

We randomly selected 1002 screening cards from a routine newborn screening program conducted by the Screening Labor Hannover. Inclusion criteria were birth between 37 and 42 weeks of gestation and sampling between the second and fourth day of life. A third inclusion criterion was the availability of a sufficient amount of dried blood. Since at least five of the six circles indicated on the filter paper can be filled in the vast majority of cases, only a few cards from routine screening program were not eligible for liquid chromatography-tandem mass spectrometry (LC-MS/MS) and genotyping. This selection was not expected to interact with any of the main outcome measurements of the study.

Quantification of 17-OHP by conventional immunoassay (TRFIA, time-resolved fluorescence immunoassay; DELFIA, PerkinElmer, Turku, Finland) as well as steroid profile measurement by LC-MS/MS was performed according to standard protocols of the Screening-Labor Hannover. LC-MS/MS steroid profile included quantification of 17-OHP, 21-deoxycortisol $(21 \mathrm{~F})$, cortisol $(\mathrm{F}), 4$-androstenedione $(4 \mathrm{~A})$, and 11-deoxycortisol (S) as well as calculation of the $21 \mathrm{~F}+17-\mathrm{OHP} / \mathrm{F}$ ratio, which has been shown to further improve screening sensitivity and specificity. A detailed description of the assay procedure and performance is given elsewhere (10). A numbered scrap of each screening card together with anonymous steroid measurement data and information on birth weight, gestational age, and postnatal age at the time samples had been taken were then sent to the University Children's Hospital Bonn for genotyping and statistical analyses. The study protocol was approved by the ethics committee of the University Hospital Bonn.

\section{Genotyping}

DNA was extracted from filter paper according to the protocol by Caggana et al. (11), with minor modifications. Briefly, a $2 \times 2 \mathrm{~mm}$ scrap was cut from each screening card by scissors and tweezers with cleaning instruments by ethanol dip and flaming until fiery red in order to avoid cross-contamination. After adding $200 \mu \mathrm{l}$ methanol, samples were air-dried in a fume hood overnight. We added $50 \mu \mathrm{l}$ water, then samples were boiled for $10 \mathrm{~min}$ and centrifuged for $3 \mathrm{~min}$ at $1200 \boldsymbol{g}$. We used $1.5 \mu \mathrm{l}$ of the supernatant as PCR template in a total reaction volume of $20 \mu \mathrm{l}$. Genotypes for the GR gene variants N363S (rs6195), R23K (rs6190), and BclI (rs41423247) were determined by standard PCR (primers N363S-F: AGTACCTCTGGAGGACAGAT, N363S-R: GTACCATTCTTAAGAAACAGA, R23K-F: CGGATCAGGAAGATAATGTGAC, R23K-R: CAGTAGCTCCTCCTCTTAGG; BclI-F: GAGCCCTATTCTT CAAACTGA; BclI-R: GGCCATCAGTTATCTACTTGAG) and restriction fragment length polymorphism (RFLP), using restriction enzymes TasI (N363S), MnlI (R23K), and BclI (BclI). Reaction conditions are available on request. The amplified regions around N363S and R23K harbor more than one enzyme restriction site. Nevertheless, wildtype, heterozygous, and homozygous samples can clearly be distinguished by RFLP (Fig. 1).

From a total of 1002 samples, genotyping was successful in 1000 samples. Two screening cards could not be included due to insufficient DNA amplification. Approximately 5\% DNA-preparations and amplifications have been repeated because of lacking or only weak bands in the first PCR-RFLP set. In addition, PCR-RFLP was repeated with all samples homozygous for $363 \mathrm{~S}$ or $23 \mathrm{~K}$ on a $3.0 \%$ agarose gel (otherwise $2.5 \%$ ) to confirm homozygosity.

\section{Statistical analysis}

Statistical analyses were performed using the SPSS software package, version 14 (SPSS Inc., Chicago, IL, USA). Since most of the variables analyzed did not follow a normal distribution, we used the MannWhitney $U$ Test and the Kruskal-Wallis non-parametric statistical analysis to compare differences between groups. For some analyses such as ANOVA, we performed log-transformation in order to obtain normal distribution. Statistical significance was assumed for $P$ values $<0.05$.

Because of the small number of samples homozygous for $363 \mathrm{~S}$ or $23 \mathrm{~K}$, those heterozygous $(+/-)$ and homozygous $(+/+)$ for the variant allele were grouped $(+/-$ and $+/+)$ for comparisons of steroid levels between genotype groups. Data in results and tables are expressed as mean \pm s.D. 

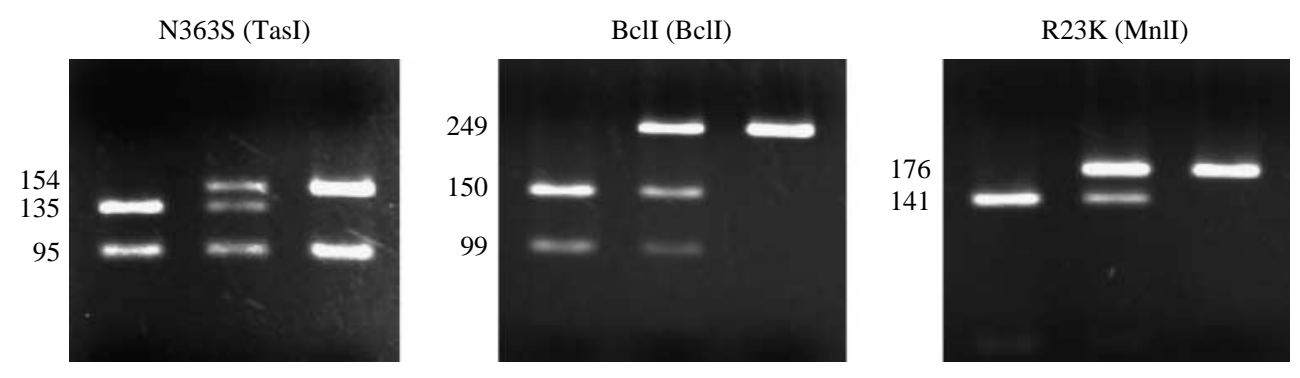

Figure 1 The $A$ to $G$ nucleotide substitution of the N363S variant truncates one of two Tasl restriction sites; fragments after Tasl digestion are $95+19+135 \mathrm{bp}$ (in $5^{\prime}-3^{\prime}$ direction) for the wildtype (N363) and $95+154 \mathrm{bp}$ for the mutant (363S) allele. A silent $\mathrm{G}$ to $A$ substitution (E22E), which is in complete linkage disequilibrium with a $G$ to $A$ substitution in the neighboring codon (R23K), together referred to as ER22/23EK ( $r$ s6189 and rs6190), truncates one of three Mnll restriction sites; fragments after Mnll digestion are $141+35+3+18 \mathrm{bp}$ for the wildtype (R23) and $176+3+18 \mathrm{bp}$ for the mutant (23K) allele. The C to G substitution of the Bcll-variant abolishes the (unique) Bcll restriction site within the amplified region; fragments are $150+99$ bp (wildtype allele) and 249 bp (Bcll-variant).

\section{Results}

From 1000 samples, 48 carried at least one 363S allele (three homozygous samples), and 39 carried the $23 \mathrm{~K}$ allele (one homozygous). For the more frequent BclI polymorphism, we found 467 heterozygous and 127 homozygous samples. Genotypes were in HardyWeinberg equilibrium; allele frequencies (363S 2.6\%; 23K $2.0 \%$; BclI $36.1 \%$ ) were comparable with those reported previously in Western European populations $(8,9,12,13)$.

Table 1 lists gestational age, birth weight, and age of the babies at the time blood samples for screening had been taken, showing no differences between genotype groups. Mean 17-OHP values from both conventional immunoassay and LC-MS/MS did not show any significant association with GR genotypes when analyzed within the total sample of 1000 screening cards. Similarly, there were no significant associations between steroid hormone measurements from LCMS/MS and GR genotypes, although we observed some unexpected trends: whereas mean 11-deoxycortisol concentrations appeared to be lower in carriers of the sensitizing $363 \mathrm{~S}$ allele $(P=0.062)$, a tendency towards the same direction was also seen in carriers of 23K $(P=0.106)$ which, in contrast, is considered to decrease GR sensitivity. Contrary to the a priori hypothesis (i.e., increased GR sensitivity would be associated with relatively lower steroid hormone concentrations) we also noted a trend towards higher 4-androstenedione levels in carriers of the BclI variant $(P=0.068)$. When comparing wildtype samples to only those homozygous for this variant, 4-androstenedione values differed with a borderline significance $(P=0.050)$. The high frequency of the BclI-variant allowed linear regression analysis in order to test for allele-dose effects. However, a significant effect was seen only on 4-androstenedione levels $(P=0.016)$; TRFIA17-OHP: $P=0.083$; remaining steroids: $P>0.2$.

To exclude compound heterozygosity or even double mutants as a possible source of biased analysis, we excluded all samples carrying more than one GR variant and repeated analysis by comparing the pure carriers of each GR variant with real non-carriers, i.e., those who did not carry any of the three variants analyzed $(n=350)$. Whereas, only one sample was excluded due to heterozygosity for both $363 \mathrm{~S}$ and $23 \mathrm{~K}$ alleles, 13 samples carried both BclI and $363 \mathrm{~S}$ alleles, and another 17 both BclI and 23K alleles. However, apart from further decreasing 11-deoxycortisol values in 23K-carriers now reaching statistical significance, differences between genotype groups remained small and did not reach statistical significance (Table 2).

Considering the high variation of 17-OHP levels, we divided 17-OHP screening values from both TRFIA and LC-MS/MS into tertiles and compared genotype frequencies between tertiles. Consistent with the trends displayed in Table 1, we noted a trend towards an increasing frequency of 363S-carriers $(10,16$, and 22 samples) from the lowest to the highest tertile of TRFIA 17-OHP levels $\left(\chi^{2}=4.732 ; P=0.094\right)$, whereas the opposite trend was observed when using tertiles of LCMS/MS 17-OHP levels (23, 14, and 11 samples, resp.; $\left.\chi^{2}=5.138, P=0.077\right)$. The distribution of $23 \mathrm{~K}$-carriers and BclI genotypes did not differ among the 17-OHP tertiles (data not shown).

Gestational age, birth weight, and timing of the screening are known to affect individual 17-OHP levels in routine screening programs. This was also seen within our sample. Spearman's rank correlation coefficients regarding TRFIA 17-OHP-values were $R=-0.22(P<0.01)$ for gestational age, $R=-0.12$ $(P<0.01)$ for birth weight, and $R=-0.14(P<0.01)$ for postnatal age respectively. Similarly, significant correlations were observed between LC-MS/MS 17-OHP-measurements and gestational age $(R=$ $-0.11 ; P<0.01)$ as well as birth weight $(R=-0.12$; $P<0.01$ ), albeit the relation between 17-OHP and postnatal age at screening did not reach statistical significance in this assay $(R=-0.05 ; P=0.99)$. Not unexpectedly, the inter-assay correlation of 17-OHP screening values obtained from TRFIA and LC-MS/MS 


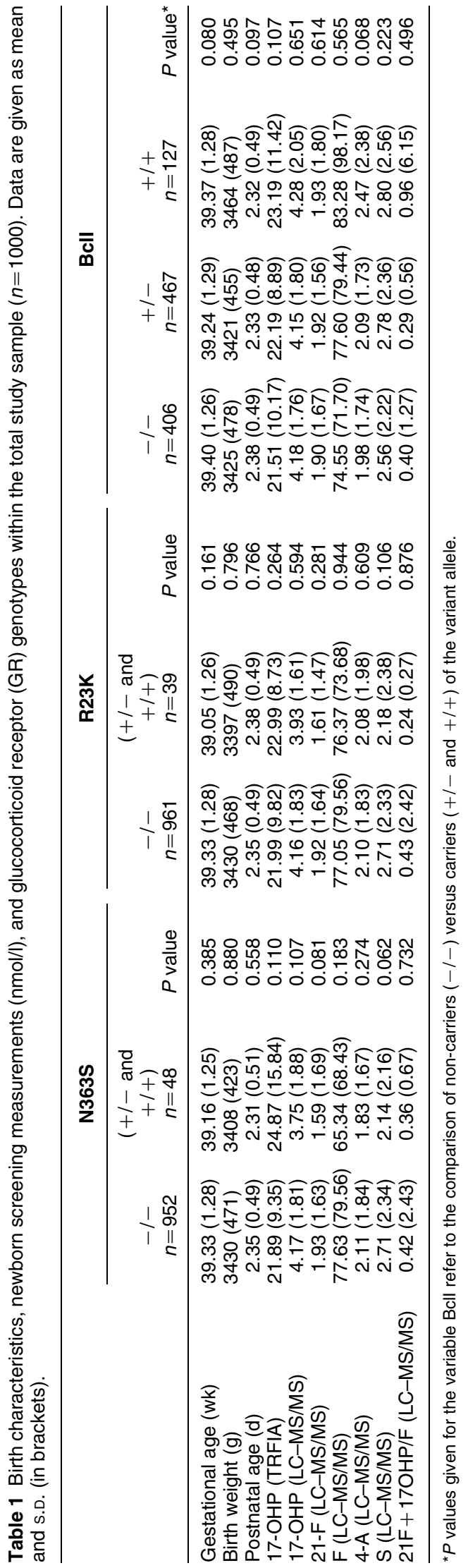

was relatively low $(R=0.28 ; P<0.01)$, which can be explained by the high cross-reactivity of the 17-OHP antibody with steroids other than 17-OHP. Finally, we added gestational age, birth weight, and postnatal age as covariates in a one-way ANOVA, but again, failed to find statistically significant genotype effects on 17-OHP screening values $(P$ values $>0.15$ )

\section{Discussion}

We here addressed the question of whether functional GR variants modify neonatal 17-OHP levels, which are routinely used as newborn screening parameter for classical CAH. In a sample of 1000 randomly selected newborn screening cards, we did not find significant associations of these variants with neonatal 17-OHP.

Although numerous clinical studies have underlined the functional relevance of human GR gene variants in both physiological and pathological conditions such as metabolism, body composition, risk of cardiovascular disease or even psychiatric conditions $(9,13)$, little is known of their biological effects in early infancy. Considering elevated 17-OHP levels in newborns affected by $\mathrm{CAH}$, a well established HPA-axis including feedback response via central GRs can be assumed during early stages of life. In our study, the vast majority of the randomly selected individuals are likely to be not affected by classical CAH. 17-OHP screening values revealed the expected broad variability, which could not be explained by the occurrence of three functional GR gene variants. Considering the recent findings of Luczay et al. which strongly indicate that genetically determined differences in glucocorticoid sensitivity can functionally affect the HPA-axis even before birth (8), one could speculate that N363S mediated effects in newborns become apparent only in conditions of a supraphysiologically stimulated HPA-axis such as in $\mathrm{CAH}$, while being undetectable or at least masked by a physiological variation due to other factors in healthy newborns. A similar hypothesis has recently been suggested by Kuningas et al. Their study on basal cortisol levels, GR genotypes, and mental performance did not reveal significant associations under nonstressful testing conditions, as opposed to previous studies that used stress-response models or were even conducted within cohorts of patients who were already affected by psychiatric disease (14).

We were aware that even within a sample restricted to screening cards taken from babies born at term (3742 weeks of gestation) with a screening performed between the second and fourth day of life both gestational and postnatal age represent a significant interfering factor concerning steroid hormone measurements $(1,15)$. To overcome this, we have repeated several statistical analyses within subgroups of equal gestational and postnatal age (e.g., 38, 39 or 40 weeks only; second or third postnatal day only), but still failed 
Table 2 Mean steroid hormone concentrations ( $\mathrm{nmol} / \mathrm{l}$ ) and s.D. (in brackets) in an adjusted model comparing real non-carriers (3 open circles) versus pure carriers ( 1 filled circle).

\begin{tabular}{|c|c|c|c|c|c|c|c|}
\hline & \multirow{2}{*}{$\begin{array}{c}\text { Noncarrier } \\
\bigcirc \bigcirc \bigcirc \\
n=350\end{array}$} & \multicolumn{2}{|c|}{$\begin{array}{c}\text { N363S } \\
\bigcirc \bigcirc \bigcirc\end{array}$} & \multicolumn{2}{|c|}{$\begin{array}{l}\text { R23K } \\
\bigcirc \bigcirc \bigcirc\end{array}$} & \multicolumn{2}{|c|}{$\begin{array}{c}\text { Bcll } \\
\bigcirc \bigcirc 0\end{array}$} \\
\hline & & $n=34$ & $P$ value & $n=21$ & $P$ value & $n=564$ & $P$ value \\
\hline 17-OHP (TRFIA) & $21.20(9.19)$ & $24.74(17.76)$ & 0.143 & $21.32(8.83)$ & 0.754 & $22.25(9.47)$ & 0.110 \\
\hline 17-OHP (LC-MS/MS) & $4.15(1.77)$ & $3.91(1.90)$ & 0.410 & $3.98(1.40)$ & 0.863 & $4.19(1.86)$ & 0.813 \\
\hline 21-F (LC-MS/MS) & $1.93(1.67)$ & $1.95(1.84)$ & 0.841 & $1.37(1.43)$ & 0.131 & $1.95(1.62)$ & 0.668 \\
\hline $\mathrm{F}(\mathrm{LC}-\mathrm{MS} / \mathrm{MS})$ & $75.21(72.26)$ & $68.93(70.79)$ & 0.496 & $69.33(66.44)$ & 0.791 & 79.32 (84.22) & 0.611 \\
\hline 4-A (LC-MS/MS) & $2.00(1.75)$ & $1.95(1.88)$ & 0.725 & $1.76(1.57)$ & 0.635 & $2.18(1.88)$ & 0.116 \\
\hline S (LC-MS/MS) & $2.63(2.25)$ & $2.44(2.09)$ & 0.698 & $1.53(1.78)$ & 0.019 & $2.80(2.39)$ & 0.395 \\
\hline $21 \mathrm{~F}+17 \mathrm{OHP} / \mathrm{F}(\mathrm{LC}-\mathrm{MS} / \mathrm{MS})$ & $0.41(1.35)$ & $0.43(0.79)$ & 0.671 & $0.24(0.27)$ & 0.908 & $0.44(2.98)$ & 0.614 \\
\hline
\end{tabular}

to find significant genotype effects (data not shown). In addition, considering that screening samples in our study were taken at a mean age of 2.4 days, placental derived steroids might still circulate in the infant's blood (16). While the placenta is not under the influence of the HPA-axis feedback regulation, this may add to the fact that no significant GR genotype effects were found. In this context, it should also be noted that opposing trends were found in respect to the distribution of $363 \mathrm{~S}$ alleles among 17-OHP tertiles between the two screening assays, with an increasing 363S-frequency from the lowest to the highest tertile in TRFIA measurements and the opposite pattern among LCMS/MS screening values. Additional studies analyzing samples taken from 5- to 6-day-old children may help to clarify these points.

Nevertheless, we did observe trends for each of the three analyzed GR variants, some of them apparently conflicting with the previously shown characteristics of the respective GR variants. Screening samples carrying the BclI variant, which, similar to N363S, is considered to increase GR sensitivity $(17,18)$, revealed a trend towards higher 4-androstenedione concentrations, in contrast to lower steroid hormone concentrations (11deoxycortisol and 21-deoxycortisol) in carriers of 363S. Linear regression analysis even revealed a statistical significance for the increase of 4-androstenedione levels in carriers of one or two BclI alleles, hereby suggesting the presence of an allele dose effect. In addition, a trend towards lower 11-deoxycortisol was seen in 363S- as well as $23 \mathrm{~K}$-carriers, the former known to increase, the latter to decrease GR sensitivity. We are aware that the findings underlying the reported functional effects of $\mathrm{N} 363 \mathrm{~S}, \mathrm{R} 23 \mathrm{~K}$, and BclI mainly derive from in vivo dexamethasone suppression tests, indicative of differences in the HPA-axis feedback response (11). Concerning basal cortisol concentrations without preceding excessive feedback stimulation, the situation might be somewhat different $(13,14)$. Similar to the trends observed in our sample, van Schoor et al. recently reported on trends towards higher basal cortisol levels in homozygous carriers of the BclI-variant as opposed to decreasing cortisol levels in individuals carrying 363S, although changes did not reach statistical significance and results were obtained in a cohort of elderly people (12). Although we do not consider the early neonatal life as an entirely non-stressful period, these findings would rather support the assumption of a relatively low stimulated HPA-axis in 2- to 4-day-old neonates than a constellation comparable with that induced by dexamethasone administration.

Moreover, the molecular mechanisms by which 363S, $23 \mathrm{~K}$, and the BclI-variant mediate their modulating effects are still poorly understood, and it is not clear whether these variants modulate glucocorticoid sensitivity in a qualitatively comparable manner. N363S and R23K lie within the transactivation domain encoded by exon 2, and in vitro experiments revealed differences in their transactivating capacities as compared with the wildtype protein (19). For N363S, marked changes in gene expression were detected by microarray studies even without ligand incubation (20). Conventional transfection assays are precluded in the case of the BclI-variant due to its intronic location. Because BclI, in addition, is not located near a known splicing site, linkage to other functional polymorphisms may underlie its phenotype. Indeed, in the study of Rautanen et al. who investigated the relationship of six GR haplotypes to basal cortisol secretion, the BclI-variant was part of two haplotypes, but only one of these two was associated with higher basal cortisol levels (21). Interestingly, steroid profiling in our study revealed a significant genotype effect for BclI on 4-androstenedione levels, whereas mineralocorticoid and glucocorticoid precursors seemed to be not or only marginally affected. Although the standard deviations for measurements of 4-androstenedione, 11-deoxycortisol, and 21-deoxycortisol were high, both mean concentration in $(\mathrm{nmol} / \mathrm{l})$ and the respective s.D. were largely comparable for these three steroids. Thus, this finding may point to an underlying mechanism considerably distinct from those mediated by N363S and R23K.

A limitation of our study is that it does not include a CAH-control group. Only by comparing individual screening values and steroid measurements from the immediate diagnostic work-up within a large cohort of CAH patients, would it be possible to transfer the findings of Luczay et al., whose data derive from patients 
who were diagnosed clinically at a mean age of 1-3 months, from early infancy to the neonatal stage. In addition, disease modifying effects, if any, for R23K and the BclI-variant in CAH-patients remain to be investigated. Recently, another genomic variant (exon 9 $\beta$-polymorphism, rs6198) has been described, which similar to $\mathrm{R} 23 \mathrm{~K}$, is related to a relative GR resistance. To date, the molecular mechanisms behind this effect are still incompletely understood. Stabilization of GR $\beta$ mRNA resulting in an accumulation of the GR $\beta$ protein with a dominant-negative effect on GR $\alpha$ action may play a role (22-24). This polymorphism is linked to R23K but also exists alone. With an allele frequency of up to $15 \%$ in European populations, this variant may provide additional information in future studies of individual glucocorticoid sensitivity and its possible relation to the incomplete genotype-phenotype correlation in $\mathrm{CAH}$.

To conclude, our results show that the GR polymorphisms N363S and R23K as well as the more common BclI-variant do not underlie the wide variation of 17-OHP screening values observed in healthy individuals, which is considered a major cause of the only reduced sensitivity of newborn screening programs for CAH. However, whether and to which extent genetically determined differences in the individual GR sensitivity influence neonatal 17-OHP levels in conditions of a pathological HPA-axis stimulation and thus may explain false-negative screening results in infants affected by $\mathrm{CAH}$ remains to be investigated.

\section{Declaration of interest}

The authors declare that they have no conflict of interest that could be perceived as prejudicing the impartiality of the research reported.

\section{Funding}

This research did not receive any specific grant from any funding agency in the public, commercial or not-for-profit sector.

\section{Acknowledgements}

We thank Dr R Fimmers, Institute of Medical Biometry, Informatics and Epidemiology, University of Bonn, for statistical advice.

\section{References}

1 Speiser PW \& White PC. Congenital adrenal hyperplasia. New England Journal of Medicine 2003349 776-788.

2 Therrell BL, Berenbaum SA, Manter-Kapanke V, Simmank J, Korman K, Prentice L, Gonzalez J \& Gunn S. Results of screening 1.9 million Texas newborns for 21-hydroxylase-deficient congenital adrenal hyperplasia. Pediatrics 1998101 583-590.

3 Votava F, Török D, Kovacs J, Möslinger D, Baumgartner-Parzer SM, Solyom J, Pribilincova Z, Battelino T, Lebl J, Frisch H, \& Waldhauser F for the Middle European Society for Paediatric Endocrinology - Congenital Adrenal Hyperplasia (MESPE-CAH)
Study Group. Estimation of the false-negative rate in newborn screening for congenital adrenal hyperplasia. European Journal of Endocrinology 2005152 869-874.

4 Schreiner F, Brack C, Salzgeber K, Vorhoff W, Woelfle J \& Gohlke B. False negative 17-hydroxyprogesterone screening in children with classical congenital adrenal hyperplasia. European Journal of Pediatrics $2008167479-481$.

5 Speiser PW, Dupont J, Zhu D, Serrat J, Buegeleisen M, Tusie-Luna MT, Lesser M, New MI \& White PC. Disease expression and molecular genotype in congenital adrenal hyperplasia due to 21-hydroxylase deficiency. Journal of Clinical Invesigation 199290 584-595.

6 Wilson RC, Mercado AB, Cheng KC \& New MI. Steroid 21-hydroxylase deficiency: genotype may not predict phenotype. Journal of Clinical Endocrinology and Metabolism 199580 2322-2329.

7 Rocha RO, Billerbeck AE, Pinto EM, Melo KF, Lin CJ, Longui CA, Mendonca BB \& Bachega TA. The degree of external genitalia virilization in girls with 21-hydroxylase deficiency appears to be influenced by the CAG repeats in the androgen receptor gene. Clinical Endocrinology $200868226-232$.

8 Luczay A, Török D, Ferenczi A, Majnik J, Solyom J \& Fekete G. Potential advantage of N363S glucocorticoid receptor polymorphism in 21-hydroxylase deficiency. European Journal of Endocrinology 2006154 859-864.

9 Van Rossum EF \& Lamberts SW. Polymorphisms in the glucocorticoid receptor gene and their associations with metabolic parameters and body composition. Recent Progress in Hormone Research $200459333-357$.

10 Janzen M, Peter M, Sander S, Steuerwald U, Terhardt M, Holtkamp U \& Sander J. Newborn screening for congenital adrenal hyperplasia: additional steroid profile using liquid chromatography-tandem mass spectrometry. Journal of Clinical Endocrinology and Metabolism 200792 2581-2589.

11 Caggana M, Conroy JM \& Pass KA. Rapid, efficient method for multiplex amplification from filter paper. Human Mutation 1998 $11404-409$.

12 Van Schoor NM, Dennison E, Lips P, Uitterlinden AG \& Cooper C. Serum fasting cortisol in relation to bone, and the role of genetic variations in the glucocorticoid receptor. Clinical Endocrinology $200767871-878$.

13 DeRijk RH, van Leeuwen N, Klok MD \& Zitman FG. Corticosteroid receptor-gene variants: modulators of the stress-response and implications for mental health. European Journal of Pharmacology $2008 \mathbf{5 8 5} 492-501$.

14 Kuningas M, de Rijk RH, Westendorp RG, Jolles J, Slagboom PE \& Heemst D. Mental performance in old age dependent on cortisol and genetic variants in the mineralcorticoid and glucocorticoid receptors. Neuropsychopharmacology 200732 1295-1301.

15 Garagorri JM, Rodriguez G, Lario-Elboj AJ, Olivares JL, LarioMunoz A \& Orden I. Reference levels for 17-hydroxyprogesterone, 11-deoxycortisol, cortisol, testosterone, dehydroepiandrosterone sulphate and androstenedione in infants from birth to six months of age. European Journal of Pediatrics 2008167 647-653.

16 Intersex and other disorders of sexual differentiation. In Practical Endocrinology and Diabetes in Children, edn 2, pp 109-126. Eds JE Raine, MD Donaldson, JW Gregory, MO Savage \& RL Hintz. Oxford: Blackwell Pub Ltd, 2006.

17 Van Rossum EF, Koper JW, van den Beld AW, Uitterlinden AG, Arp P, Ester W, Janssen JA, Brinkmann AO, de Jong FH, Grobbee DE, Pols HA \& Lamberts SW. Identification of the BclI polymorphism in the glucocorticoid receptor gene: association with sensitivity to glucocorticoids in vivo and body mass index. Clinical Endocrinology $2003 \mathbf{5 9} 585-592$.

18 Stevens A, Ray DW, Zeggini E, John S, Richards HL, Griffiths CE \& Donn R. Glucocorticoid sensitivity is determined by a specific glucocorticoid receptor haploype. Journal of Clinical Endocrinology and Metabolism $200489892-897$.

19 Russcher H, Smit P, van der Akker EL, van Rossum EF, Brinkman AO, de Jong FH, Lamberts SW \& Koper JW. Two polymorphisms in the glucocorticoid receptor gene directly affect glucocorticoid-regulated gene expression. Journal of Clinical Endocrinology and Metabolism 200590 5804-5810. 
20 Jewell CM \& Cidlowski JA. Molecular evidence for a link between the N363S glucocorticoid receptor polymorphism and altered gene expression. Journal of Clinical Endocrinology and Metabolism $2007923268-3277$.

21 Rautanen A, Eriksson JG, Kere J, Andersson S, Osmond C, Tienari P, Sairanen H, Barker DJ, Phillips DI, Forsen T \& Kajantie E. Associations of body size at birth with late-life cortisol concentrations and glucose tolerance are modified by haplotypes or the glucocorticoid receptor gene. Journal of Clinical Endocrinology and Metabolism 200691 4544-4551.

22 Van den Akker EL, Nouwen JL, Melles DC, van Rossum EF, Koper JW, Uitterlinden AG, Hofman A, Verbrugh HA, Pols HA Lamberts SW \& van Belkum A. Staphylococcus aureus nasal carriage is associated with glucocorticoid receptor gene polymorphisms. Journal of Infectious Disease 2006194 814-818.
23 DeRijk RH, Schaaf MJ, Turner G, Datson NA, Vreugdenhil E, Cidlowski J, de Kloet ER, Emery P, Sternberg EM \& DeteraWadleigh SD. A human glucocorticoid receptor gene variant that increases the stability of the glucocorticoid receptor beta-isoform mRNA is associated with rheumatoid arthritis. Journal of Rheumatology 200128 2383-2388.

24 Schaaf MJ \& Cidlowski JA. AUUUA motifs in the $3^{\prime}$ UTR of human glucocorticoid receptor alpha and beta mRNA destabilize mRNA and decrease receptor protein expression. Steroids 200267 $627-636$.

Received 5 January 2009

Accepted 26 January 2009 